\title{
Relationship between autonomic cardiovascular control and obstructive sleep apnoea in persons with spinal cord injury: a retrospective study
}



Received: 15 August 2017 / Revised: 16 January 2018 / Accepted: 26 February 2018

(c) International Spinal Cord Society 2018

\begin{abstract}
Study design Retrospective study

Objective To determine if there is an association between obstructive sleep apnoea (OSA) and blood pressure (BP) pattern or heart rate variability (HRV) in people with spinal cord injury (SCI)

Setting A state-based spinal cord service in Victoria, Australia.

Methods We identified 42 subjects who had ambulatory BP monitoring (ABPM) within 6 months of a diagnostic sleep study at Austin Hospital between 2009 and 2014. Markers for autonomic function, including circadian BP pattern and HRV were extracted from the ABPM study database. Apnoea/hypopnoea index (AHI), arousals/hour and oxygen desaturation index were extracted from the sleep study database. Subjects with a nocturnal systolic BP dipping more than $10 \%$ of daytime value were defined as dippers, between 10 and $0 \%$ were non-dippers and those with a higher night than day systolic BP were reverse dippers. Severity of OSA is classified as non-OSA (AHI <5), mild (AHI 5-15), moderate (AHI 15-30) and severe (AHI > 30).

Results Subjects $(n=42)$ were predominantly male $(85.7 \%)$, aged $44 \pm 15.4$ (mean \pm SD), with a BMI of $24.4 \pm 5.7$ (mean \pm SD) and mainly tetraplegic $(92.9 \%)$. There was no difference in AHI, oxygen desaturation index or arousals/hour between dippers, non-dippers and reverse dippers. None of the HRV parameters differed between dippers, non-dippers and reverse dippers. No differences were found in $24 \mathrm{~h}$, night-time, daytime or nocturnal dip in BP between subjects with non-OSA, mild, moderate and severe OSA.
\end{abstract}

Conclusion We found no relationship between BP pattern or HRV and the severity of OSA in persons with SCI.

\section{Introduction}

People with spinal cord injury (SCI) often suffer from autonomic dysfunction, which is proposed to contribute to increased mortality from cardiovascular and respiratory disease [1, 2]. Studies on the able-bodied population have revealed a relationship between obstructive sleep apnoea

Xizhe Fang

fxz802@gmail.com

1 Institute for Breathing and Sleep Austin Hospital Heidelberg, VIC, Australia

2 University of Melbourne Melbourne, VIC, Australia

3 Department of Clinical Pharmacology Austin Hospital Heidelberg, VIC, Australia

4 The Spinal Research Institute Melbourne, VIC, Australia
(OSA), hypertension, altered diurnal blood pressure (BP) patterns [3] and heart rate variability (HRV) [4, 5].

In healthy, able-bodied people, BP generally falls during sleep. Loss of nocturnal BP dipping, i.e., a failure of nocturnal systolic BP (SBP) to fall to $<90 \%$ of the day value [6] as well as reduced HRV and vagal cardiac tone are associated with adverse cardiovascular outcomes [79]. OSA contributes to abnormalities of the BP pattern and HRV in the able-bodied population [3-5, 10]. However, to our knowledge, the relationship between OSA and circadian BP pattern or HRV has not been studied in the SCI population. It may be important to consider the impact of OSA in the setting of altered cardiovascular autonomic control in people with SCI. In this study, we used circadian BP pattern and HRV as markers for autonomic function and investigated the association between these markers and the severity of OSA in people with SCI. 


\section{Methods}

\section{Subjects and setting}

Our study was approved by the Austin Health Human Research Ethics Committee. As this study involved only retrospective review of the medical records, patient consent was not required. Potential subjects were identified by reviewing inpatient or outpatient records of patients who attended a state-based SCI service between 2009 and 2014. Subjects entered the study if they had a traumatic SCI and had undergone a sleep study or ambulatory BP and electrocardiography monitoring on a combination device (Card (X)plore monitor, Meditech, Budapest, Hungary). Individuals with both a sleep study and ambulatory BP monitoring $(\mathrm{ABPM})$ were identified and common data were extracted. Diagnostic sleep studies performed within 6 months of the ABPM study were selected. For subjects with multiple qualifying pairs (sleep study and ABPM), the most recent were included.

Fifty-six participants were initially identified. Fourteen were excluded because two had brain stem lesions, 11 had incomplete ABPM study data and one had inadequate sleep study results.

\section{Data extraction}

Data extracted from the medical records of the 42 final participants included age, gender, height, weight, time from injury, level of injury and neurological classification (American Spinal Injuries Association impairment scale, AIS [11]).

Ambulatory BP measurements were analysed as mean 24 h, day (10 a.m. -8 p.m.) and night (12-6 a.m.) BP and pulse rate (PR). Medication usage and intercurrent illnesses were recorded. The nocturnal BP dip was calculated as follows for SBP and diastolic BP (DBP): [100\% $\times$ (average day BP - average night BP)/average day BP]. Subjects were defined as dippers, non-dippers and reversed dippers if compared to the day SBP, the nocturnal SBP was at least $10 \%$ less, between 10 and $0 \%$ less or greater [6]. Hypertension was defined as a $24 \mathrm{~h} \mathrm{BP}$ above $130 / 80 \mathrm{~mm} \mathrm{Hg}$, day hypertension as day BP above 135/85 $\mathrm{mm} \mathrm{Hg}$ and nocturnal hypertension as a night $\mathrm{BP}$ above $120 \mathrm{~mm} \mathrm{Hg} \mathrm{SBP}$ or $70 \mathrm{~mm} \mathrm{Hg} \mathrm{DBP,} \mathrm{according} \mathrm{to} \mathrm{clinical} \mathrm{guidelines} \mathrm{[12].}$

The HRV indices were obtained from the Cardiovisions 1.19 software (Meditech), and was analysed according to time and frequency domain. The following measures were obtained in the time domain: the standard deviation (SD) of normal to normal intervals (SDNN); the SD of the average normal to normal intervals calculated over segments of 5 min (SDANN); the percentage of consecutive RRs that
Table 1 Characteristics of study groups

\begin{tabular}{|c|c|c|c|c|c|}
\hline & Dipper & $\begin{array}{l}\text { Non- } \\
\text { dipper }\end{array}$ & $\begin{array}{l}\text { Reverse } \\
\text { dipper }\end{array}$ & All & $\begin{array}{l}P \text { - } \\
\text { value }\end{array}$ \\
\hline$n$ & 5 & 16 & 21 & 42 & \\
\hline Age (SD) & $\begin{array}{l}52.6 \pm \\
15.7\end{array}$ & $\begin{array}{l}46.9 \pm \\
12.7\end{array}$ & $\begin{array}{l}39.7 \pm \\
16.6\end{array}$ & $\begin{array}{l}44.0 \pm \\
15.4\end{array}$ & 0.153 \\
\hline Gender (F) $(\%)$ & $\begin{array}{l}2 \\
(40.0)\end{array}$ & $1(6.3)$ & $3(14.3)$ & $\begin{array}{l}6 \\
(14.3)\end{array}$ & 0.170 \\
\hline BMI $\left(\mathrm{kg} / \mathrm{m}^{2}\right)(\mathrm{SD})$ & $\begin{array}{l}22.5 \pm \\
4.0, \\
n=4\end{array}$ & $\begin{array}{l}25.7 \pm \\
5.1, \\
n=15\end{array}$ & $\begin{array}{l}23.8 \pm 6.4 \\
, n=20\end{array}$ & $\begin{array}{l}24.4 \pm \\
5.7 \\
n=39\end{array}$ & 0.432 \\
\hline No. (\%) of acute SCI & $\begin{array}{l}2 \\
(40.0)\end{array}$ & $\begin{array}{l}13 \\
(81.3)\end{array}$ & $13(61.9)$ & $\begin{array}{l}28 \\
(66.7)\end{array}$ & 0.188 \\
\hline No. of cervical SCI (\%) & $\begin{array}{l}5 \\
(100.0)\end{array}$ & $\begin{array}{l}14 \\
(87.5)\end{array}$ & $20(95.2)$ & $\begin{array}{l}39 \\
(92.9)\end{array}$ & 0.534 \\
\hline No. of AIS D (\%) & $\begin{array}{l}2 \\
(40.0)\end{array}$ & $1(6.3)$ & $1(4.8)$ & $4(9.5)$ & 0.104 \\
\hline $\begin{array}{l}\text { No. of complete SCI } \\
\text { (AIS A) }(\%)\end{array}$ & $\begin{array}{l}1 \\
(20.0)\end{array}$ & $8(50.0)$ & $12(57.1)$ & $\begin{array}{l}21 \\
(50.0)\end{array}$ & 0.328 \\
\hline
\end{tabular}

$P$-values are for comparison between dippers, non-dippers and reverse dippers

$S C I$ spinal cord injury, BMI body mass index, AIS American Spinal Injuries Association impairment scale

differed by $>50 \mathrm{~ms}$ (pNN50); and the square root of the mean squared differences of successive normal to normal intervals (rMSSD). The HRV frequency domain was analysed in low frequency (LF), high frequency (HF) and LF/ HF ratio. Power was expressed in both absolute and normalised units.

From the sleep study, apnoea/hypopnoea index (AHI), number of arousals/hour and oxygen desaturation index were extracted. The severity of OSA was defined as mild (AHI 5-15), moderate (AHI 15-30), severe (AHI > 30) and non-OSA if $\mathrm{AHI}<5$ [13].

\section{Study group}

Subjects were classified in two ways; by the dipping status (dipper, non-dipper and reverse dipper), and separately, by the severity of OSA (non-OSA, mild, moderate and severe). The time from injury was dichotomised into acute and intermediate ( $\leq 6$ months) and chronic SCI ( $>6$ months) [14].

\section{Statistical analysis}

Microsoft Excel was used for preliminary analysis, including calculating means, SDs and standard error of mean (SEM) of each variable.

Due to the small sample size of some subgroups, the Fisher exact test was performed using the $\mathrm{R}$ software 
Table 2 Details of SCI

\begin{tabular}{|c|c|c|c|}
\hline Subject & Time from injury & Injury level & AIS score \\
\hline 1 & 3 months & $\mathrm{C} 4$ & $\mathrm{~B}$ \\
\hline 2 & 1 month & $\mathrm{C} 4$ & $\mathrm{D}$ \\
\hline 3 & 1 month & C6 & $\mathrm{B}$ \\
\hline 4 & 5 months & $\mathrm{C} 4$ & A \\
\hline 5 & 1 month & C6 & B \\
\hline 6 & $<1$ month & $\mathrm{T} 5$ & A \\
\hline 7 & 1 month & $\mathrm{C} 5$ & A \\
\hline 8 & 1 month & C6 & $\mathrm{B}$ \\
\hline 9 & 1 month & $\mathrm{C} 6$ & $\mathrm{C}$ \\
\hline 10 & 1 month & $\mathrm{C} 5$ & A \\
\hline 11 & 3 months & $\mathrm{C} 3$ & A \\
\hline 12 & 1 month & $\mathrm{C} 5$ & A \\
\hline 13 & 4 months & $\mathrm{C} 3$ & A \\
\hline 14 & 2 months & $\mathrm{C} 8$ & A \\
\hline 15 & 1 month & C6 & A \\
\hline 16 & 1 month & $\mathrm{C} 5$ & $\mathrm{C}$ \\
\hline 17 & 5 months & $\mathrm{C} 4$ & $\mathrm{~B}$ \\
\hline 18 & 2 months & T6 & $\mathrm{C}$ \\
\hline 19 & 3 months & $\mathrm{C} 5$ & A \\
\hline 20 & 3 months & $\mathrm{C} 5$ & $\mathrm{D}$ \\
\hline 21 & 4 months & $\mathrm{C} 4$ & $\mathrm{~B}$ \\
\hline 22 & 3 months & $\mathrm{C} 5$ & A \\
\hline 23 & 4 months & $\mathrm{C} 5$ & $\mathrm{~B}$ \\
\hline 24 & 4 months & $\mathrm{C} 5$ & $\mathrm{~B}$ \\
\hline 25 & 4 months & $\mathrm{C} 5$ & $\mathrm{C}$ \\
\hline 26 & 2 months & $\mathrm{C} 1$ & B \\
\hline 27 & 1 month & $\mathrm{C} 5$ & A \\
\hline 28 & 5 months & $\mathrm{C} 3$ & $\mathrm{D}$ \\
\hline 29 & 3 years & $\mathrm{T} 2$ & B \\
\hline 30 & 3 years & $\mathrm{C} 5$ & A \\
\hline 31 & 7 years & C6 & A \\
\hline 32 & 6 years & $\mathrm{C} 5$ & A \\
\hline 33 & 26 years & $\mathrm{C} 4$ & A \\
\hline 34 & 2 years & $\mathrm{C} 4$ & $\mathrm{C}$ \\
\hline 35 & 26 years & $\mathrm{C} 5$ & A \\
\hline 36 & 51 years & C6 & $\mathrm{D}$ \\
\hline 37 & 9 years & $\mathrm{C} 5$ & $\mathrm{~B}$ \\
\hline 38 & 18 years & $\mathrm{C} 5$ & A \\
\hline 39 & 13 years & $\mathrm{C} 6$ & A \\
\hline 40 & 13 years & $\mathrm{C} 4$ & A \\
\hline 41 & 12 years & $\mathrm{C} 6$ & B \\
\hline 42 & 2 years & $\mathrm{C} 5$ & A \\
\hline
\end{tabular}

(http://www.r-project.org) for the analysis of categorical data, including gender, acute and intermediate/chronic SCI, cervical thoracic SCI, AIS classification of $\mathrm{A} / \mathrm{B} / \mathrm{C}$ or $\mathrm{D}$, and the completeness of the injury.
SPSS was used for other statistical analysis. Test of normality was performed for each variable. Analysis of variance and $t$-test were used to compare means of normally distributed continuous variables. With skewed data (body mass index (BMI), ODI4\%, day SBP, night PR, $24 \mathrm{~h}$ PR, SDANN, pNN50, rMSSD, LF, HF and LF/HF), $\log 10$ transformation was performed before running tests, pNN50 and LF remained skewed after transformation, for which Kruskal-Wallis test was performed. A $P$-value $<0.05$ was considered significant.

\section{Results}

\section{Participant characteristics}

Participants $(n=42)$ were predominantly male $(85.7 \%)$, aged $44 \pm 15.4$ (mean $\pm \mathrm{SD})$, with a BMI of $24.4 \pm 5.7(n=$ 39 , mean \pm SD) and mainly tetraplegic (92.9\%; Table 1). The injury levels of the 3 subjects with paraplegia were T3, T5 and T6. Twenty-eight participants had an acute/intermediate injury and 21 had complete SCI (AIS A; Table 2).

Of the 42 participants, $21(50 \%)$ were reverse dippers and 5 were dippers $(11.9 \%)$. No association was found between dipping status and age, gender, BMI, time from injury, completeness or level of injury (Table 1). Fourteen (33\%) subjects had nocturnal hypertension while only one (2\%) had daytime hypertension.

Six (14.3\%) subjects were non-OSA and 19 had severe OSA with an AHI $>30$. No relationships were found between the severity of OSA and age, gender, BMI, time from injury, completeness of injury or level of injury (data not shown).

\section{BP and OSA}

The AHI, ODI4\% and arousal index were compared between dippers, non-dippers and reverse dippers, which showed no difference across each subgroup (Table 3).

In people with acute/intermediate SCI, the AHI was significantly lower in reverse dippers $(15.2 \pm 4.2$, mean \pm SEM, $p=0.017)$ compared to dippers $(35.7 \pm 4.2)$ and nondippers $(34.2 \pm 5.0)$, while no difference was found in subjects with chronic SCI (Figs. 1 and 2).

Between people with and without nocturnal hypertension, there was no significant difference in AHI, ODI4\% or arousal index (data not shown).

\section{BP and HRV}

No significant differences were found in any of the HRV parameters between dippers, non-dippers and reverse dippers (Table 3). 
Table 3 OSA, HRV and BP vs. dipping status

\begin{tabular}{|c|c|c|c|c|c|}
\hline & All & Dipper & Non-dipper & Reverse dipper & $P$-value \\
\hline$n$ & 42 & 5 & 16 & 21 & \\
\hline \multicolumn{6}{|l|}{ OSA events } \\
\hline AHI & $25.1 \pm 2.8$ & $25.0 \pm 5.7$ & $32.1 \pm 4.3$ & $19.7 \pm 4.2$ & 0.124 \\
\hline ODI4\% (per h) & $10.0 \pm 1.8$ & $10.7 \pm 3.9$ & $12.9 \pm 3.5$ & $7.6 \pm 2.3$ & 0.171 \\
\hline Arousals (per h) & $21.3 \pm 1.9$ & $19.0 \pm 4.3$ & $25.8 \pm 2.5$ & $18.5 \pm 2.9$ & 0.165 \\
\hline \multicolumn{6}{|l|}{$\mathrm{SBP}(\mathrm{mm} \mathrm{Hg})$} \\
\hline $24 \mathrm{~h} \mathrm{SBP}$ & $111.6 \pm 1.5$ & $107.7 \pm 4.9$ & $112.3 \pm 2.6$ & $112.1 \pm 1.9$ & 0.622 \\
\hline Night-time SBP & $111.3 \pm 1.8$ & $96.1 \pm 4.3$ & $108.9 \pm 2.7$ & $116.8 \pm 1.9$ & $<0.001$ \\
\hline Daytime SBP & $110.1 \pm 1.5$ & $115.8 \pm 6.1$ & $112.9 \pm 2.6$ & $106.6 \pm 1.6$ & 0.061 \\
\hline Nocturnal SBP dip (\%) & $-1.4 \pm 1.6$ & $16.9 \pm 1.4$ & $3.6 \pm 0.7$ & $-9.6 \pm 1.1$ & $<0.001$ \\
\hline \multicolumn{6}{|l|}{ DBP $(\mathrm{mm} \mathrm{Hg})$} \\
\hline $24 \mathrm{~h}$ DBP & $64.8 \pm 1.1$ & $61.8 \pm 1.8$ & $66.4 \pm 1.9$ & $64.4 \pm 1.4$ & 0.410 \\
\hline Night time DBP & $63.0 \pm 1.3$ & $52.9 \pm 2.0$ & $63.0 \pm 2.3$ & $65.4 \pm 1.6$ & 0.013 \\
\hline Daytime DBP & $65.5 \pm 1.0$ & $68.1 \pm 2.2$ & $68.1 \pm 1.9$ & $62.9 \pm 1.2$ & 0.038 \\
\hline Nocturnal DBP dip (\%) & $3.4 \pm 1.9$ & $22.0 \pm 3.5$ & $7.4 \pm 2.6$ & $-4.0 \pm 1.9$ & $<0.001$ \\
\hline \multicolumn{6}{|l|}{ PR (bpm) } \\
\hline $24 \mathrm{~h}$ PR & $70.2 \pm 1.9$ & $68.6 \pm 2.8$ & $72.2 \pm 3.7$ & $69.1 \pm 2.5$ & 0.799 \\
\hline Night time PR & $65.5 \pm 2.0$ & $62.0 \pm 2.5$ & $64.6 \pm 3.9$ & $67.1 \pm 2.7$ & 0.681 \\
\hline Daytime PR & $73.4 \pm 2.0$ & $73.9 \pm 4.1$ & $76.5 \pm 3.7$ & $71.0 \pm 2.7$ & 0.444 \\
\hline \multicolumn{6}{|l|}{ HRV } \\
\hline SDNN & $114.4 \pm 7.4$ & $105.4 \pm 14.7$ & $120.1 \pm 15.7$ & $112.6 \pm 8.9$ & 0.810 \\
\hline SDANN & $118.7 \pm 10.5$ & $176.8 \pm 53.9$ & $120.9 \pm 15.1$ & $102.6 \pm 10.3$ & 0.202 \\
\hline pNN50 & $0.095 \pm 0.017$ & $0.050 \pm 0.033$ & $0.071 \pm 0.018$ & $0.124 \pm 0.029$ & 0.233 \\
\hline rMSSD & $31.4 \pm 2.7$ & $23.8 \pm 5.0$ & $27.9 \pm 4.0$ & $35.8 \pm 4.2$ & 0.242 \\
\hline $\mathrm{LF}$ & $687.8 \pm 97.2$ & $384.4 \pm 108.3$ & $695.7 \pm 165.3$ & $758.2 \pm 147.1$ & 0.262 \\
\hline $\mathrm{HF}$ & $462.6 \pm 87.9$ & $244.8 \pm 123.0$ & $383.6 \pm 95.0$ & $572.4 \pm 153.4$ & 0.508 \\
\hline $\mathrm{LF} / \mathrm{HF}$ & $2.05 \pm 0.18$ & $2.68 \pm 0.88$ & $2.04 \pm 0.25$ & $1.91 \pm 0.22$ & 0.757 \\
\hline
\end{tabular}

$P$-values are for comparison between dippers, non-dippers and reverse dippers. $P$-values $<0.05$ are indicated in bold

Values are means \pm SEM

$B P$ blood pressure, $H R V$ heart rate variability, $O S A$ obstructive sleep apnoea, $S B P$ systolic blood pressure, $D B P$ diastolic blood pressure, $P R$ pulse rate, $S D N N$ standard deviation of NN intervals, $S D A N N$ standard deviation of average NN intervals calculated over segments of 5 min, $p N N 50$ the percentage of consecutive RRs that differed by $>50 \mathrm{~ms}, r M S S D$ the square root of the mean squared differences of successive NN intervals, $L F$ low frequency, $H F$ high frequency

\section{OSA, BP and HRV}

No difference was found in $24 \mathrm{~h}$, night-time, daytime or nocturnal dip in SBP, DBP or PR between subjects with various degrees of OSA.

None of the HRV parameters differed in people with non-OSA, mild OSA, moderate OSA and severe OSA (Table 4).

\section{Discussion}

To our knowledge, this is the first study on the relationships between OSA and autonomic cardiovascular control in the
SCI population. Despite the hypothesis that in SCI OSA may cause a change in BP pattern [15-17], there is little direct evidence to support this speculation. In the ablebodied population, OSA can cause hypertension [18, 19], increased nocturnal BP [3] and sympathetic excitation resulting in altered HRV [20], which may contribute to cardiovascular disease. In the SCI population, cardiovascular disorders due to autonomic dysfunction are major causes of morbidity and mortality [1]. Given the high prevalence of OSA in this population, its role in the pathogenesis of or as a consequence of autonomic dysfunction, should be considered. However, in our study we were unable to demonstrate any significant relationship between BP pattern or HRV and OSA severity in people with SCI. 


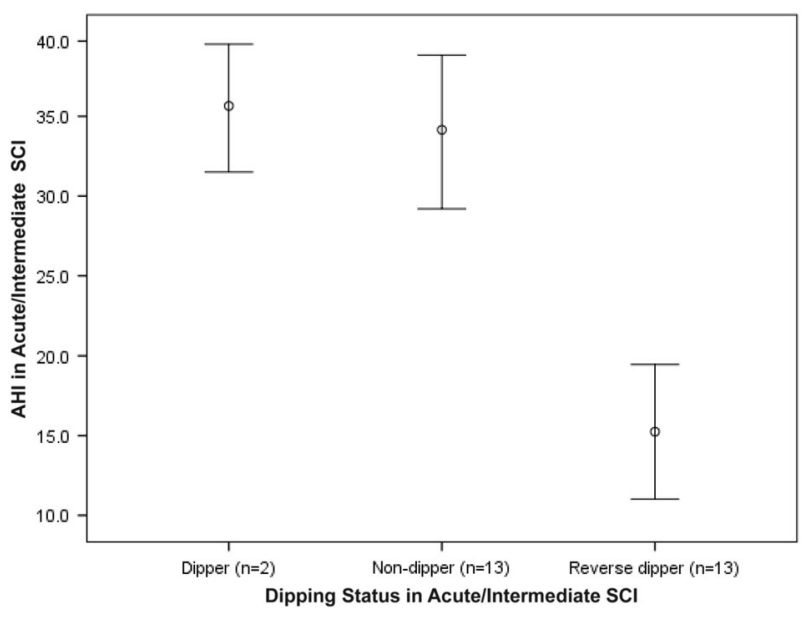

Fig. 1 AHI vs. dipping status in acute/intermediate SCI. Mean \pm SEM plot. Dippers $(35.7 \pm 4.2, n=2)$, non-dippers $(34.2 \pm 5.0, n=13)$ and reverse dippers $(15.2 \pm 4.2, n=13), P=\mathbf{0 . 0 1 7}$. Bold value represents statistically significant difference in AHI between the three groups

\section{Features of study groups}

A majority of our subjects had a disturbed pattern of circadian BP (37 of 42), consistent with the nature of highlevel SCI. As previously reported, the circadian BP pattern is altered in people with cervical SCI featuring a lower daytime BP and similar night-time BP, which is presented as a loss of nocturnal dip [21]. However, all of the 5 dippers had cervical SCI, while the 3 thoracic SCI individuals were either non-dippers or reverse dippers. This could partly be due to the small sample size of dippers and people with thoracic SCI.

Only a small proportion of our study group did not have OSA (6 out of 42). The high incidence of OSA in our study group could be explained by selection bias. Second, the high prevalence of OSA in the SCI population could also be a contributing factor.

\section{BP pattern vs. OSA}

The prevalence of loss of nocturnal BP dip and OSA were both high in our population. We did not find an association between the severity of OSA and BP pattern despite our initial hypothesis. (Tables 3 and 4). These findings suggest that the mechanisms behind $\mathrm{BP}$ variation in the setting of SCI might be different from that in the able-bodied population.

Anatomically, the sympathetic pathway is disrupted in SCI, which results in lower day BP compared to the ablebodied population, and hence reduced diurnal $\mathrm{BP}$ variation [22-24]. From the ABPM data we found that only one of the 42 subjects had daytime hypertension, while $33 \%$ had nocturnal hypertension. Half our population had night-time pressures higher than daytime pressures; this is in keeping

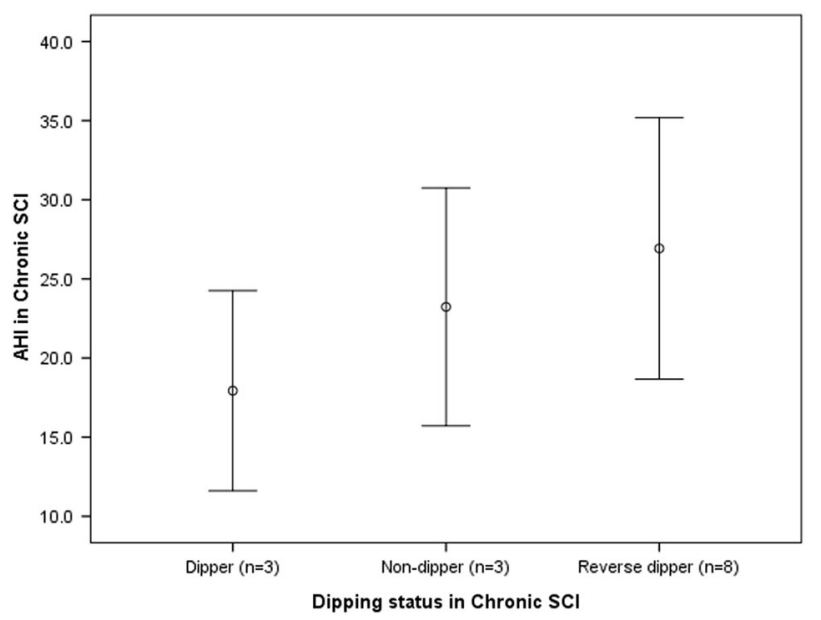

Fig. 2 AHI vs. dipping status in chronic SCI. Mean \pm SEM plot. Dippers $(17.9 \pm 6.3, n=3)$, non-dippers $(23.2 \pm 7.5, n=3)$ and reverse dippers $(26.9 \pm 8.3, n=8)$ and $P=0.802$

with previous studies that compared diurnal BP between paraplegia, tetraplegia and able-bodied controls, and observed that in people with high-level SCI (above T6), the day BP was lower compared to low-level injury and controls, whilst no differences were noticed in night BP [2229]. Therefore, the pathology of OSA and non-dipping status in the SCI population presumably relates to lower daytime, but preserved night-time BP, while in the ablebodied populations surges in night-time sympathetic activity during an apnoeic/hypopnoeic event contributes to nondipping status. In the able-bodied population, most studies investigating the relationship between BP pattern and OSA have focused on people with hypertension, nocturnal hypertension or resistant hypertension, but the same underlying mechanisms may not apply to SCI. The apnoeic/ hypopnoeic event in OSA can lead to hypoxia, which triggers cortical arousals and was found to relate to sympathetic activation in HRV studies [20]. The excitation of sympathetic nervous system is believed to contribute to the elevation of nocturnal BP in OSA patients, and hence results in the reduction in nocturnal BP dip. Given that SCI patients have lost the supraspinal sympathetic control, it is not surprising that even during apnoeic/hypopnoeic events the sympathetic activity might remain low in people with SCI, and thus no elevation in BP occurs. Therefore, although both are non-dippers, the one with SCI is most likely to have a lower daytime BP and normal night-time $\mathrm{BP}$, while the able-bodied person tends to have a higher night-time BP and normal or higher daytime BP.

The disturbance of BP pattern in people with SCI could also be explained by a loss of circadian rhythm in this population, especially in cervical SCI. During the night, in a dark environment, the pineal gland secretes melatonin [30], which exerts important cardiovascular effects [31]. A meta- 
Table 4 BP pattern and HRV vs. OSA severity

\begin{tabular}{|c|c|c|c|c|c|c|}
\hline & All & Non-OSA & Mild OSA & Moderate OSA & Severe OSA & $P$-value \\
\hline$n$ & 42 & 6 & 10 & 7 & 19 & \\
\hline \multicolumn{7}{|l|}{$\mathrm{SBP}(\mathrm{mm} \mathrm{Hg})$} \\
\hline $24 \mathrm{~h} \mathrm{SBP}$ & $111.6 \pm 1.5$ & $108.7 \pm 1.8$ & $113.2 \pm 3.7$ & $115.7 \pm 3.4$ & $110.2 \pm 2.2$ & 0.475 \\
\hline Night-time SPB & $111.3 \pm 1.8$ & $113.2 \pm 2.3$ & $110.7 \pm 4.9$ & $117.4 \pm 4.4$ & $108.8 \pm 2.4$ & 0.397 \\
\hline Daytime SBP & $110.1 \pm 1.5$ & $104.4 \pm 2.3$ & $111.8 \pm 3.1$ & $112.7 \pm 2.8$ & $110.0 \pm 2.7$ & 0.423 \\
\hline Nocturnal SBP dip (\%) & $-1.4 \pm 1.6$ & $-8.5 \pm 2.1$ & $1.0 \pm 3.3$ & $-4.2 \pm 3.2$ & $0.5 \pm 2.5$ & 0.186 \\
\hline \multicolumn{7}{|l|}{$\mathrm{DBP}(\mathrm{mm} \mathrm{Hg})$} \\
\hline $24 \mathrm{~h} \mathrm{DBP}$ & $64.8 \pm 1.1$ & $61.4 \pm 2.4$ & $64.6 \pm 2.3$ & $65.8 \pm 2.2$ & $65.7 \pm 1.7$ & 0.594 \\
\hline Night-time DBP & $63.0 \pm 1.3$ & $61.9 \pm 2.9$ & $59.6 \pm 2.5$ & $66.1 \pm 3.6$ & $63.9 \pm 2.1$ & 0.456 \\
\hline Daytime DBP & $65.5 \pm 1.0$ & $60.8 \pm 2.3$ & $66.5 \pm 2.3$ & $65.0 \pm 1.5$ & $66.6 \pm 1.7$ & 0.302 \\
\hline Nocturnal DBP dip (\%) & $3.4 \pm 1.9$ & $-2.0 \pm 3.7$ & $9.6 \pm 3.9$ & $-1.8 \pm 5.0$ & $3.7 \pm 2.9$ & 0.189 \\
\hline \multicolumn{7}{|l|}{ PR (bpm) } \\
\hline $24 \mathrm{~h}$ PR & $70.2 \pm 1.9$ & $66.7 \pm 5.2$ & $70.8 \pm 4.3$ & $78.1 \pm 4.9$ & $68.1 \pm 2.4$ & 0.285 \\
\hline Night-time PR & $65.5 \pm 2.0$ & $63.1 \pm 5.5$ & $66.2 \pm 4.7$ & $73.1 \pm 6.2$ & $63.1 \pm 2.4$ & 0.429 \\
\hline Daytime PR & $73.4 \pm 2.0$ & $70.6 \pm 5.9$ & $74.7 \pm 4.2$ & $81.1 \pm 4.5$ & $70.9 \pm 2.9$ & 0.327 \\
\hline \multicolumn{7}{|l|}{ HRV } \\
\hline SDNN & $114.4 \pm 7.4$ & $126.7 \pm 17.2$ & $113.2 \pm 15.6$ & $96.4 \pm 19.6$ & $118.0 \pm 11.2$ & 0.674 \\
\hline SDANN & $118.7 \pm 10.5$ & $128.8 \pm 25.4$ & $120.3 \pm 23.4$ & $88.6 \pm 19.2$ & $126.6 \pm 17.2$ & 0.390 \\
\hline pNN50 & $0.095 \pm 0.017$ & $0.157 \pm 0.054$ & $0.130 \pm 0.052$ & $0.044 \pm 0.023$ & $0.077 \pm 0.015$ & 0.217 \\
\hline rMSSD & $31.4 \pm 2.7$ & $43.5 \pm 8.4$ & $34.1 \pm 7.4$ & $21.3 \pm 4.2$ & $29.9 \pm 3.0$ & 0.181 \\
\hline $\mathrm{LF}$ & $687.8 \pm 97.2$ & $997.8 \pm 322.7$ & $748.9 \pm 214.2$ & $323.7 \pm 122.5$ & $696.0 \pm 140.9$ & 0.262 \\
\hline $\mathrm{HF}$ & $462.6 \pm 87.9$ & $804.0 \pm 366.0$ & $582.7 \pm 234.1$ & $208.0 \pm 101.4$ & $383.4 \pm 78.2$ & 0.295 \\
\hline $\mathrm{LF} / \mathrm{HF}$ & $2.05 \pm 0.18$ & $1.60 \pm 0.32$ & $1.80 \pm 0.33$ & $2.24 \pm 0.41$ & $2.26 \pm 0.32$ & 0.649 \\
\hline
\end{tabular}

$P$-values are for comparison between people with non-OSA, mild, moderate and severe OSA

Values are means \pm SEM

$B P$ blood pressure, $H R V$ heart rate variability, $O S A$ obstructive sleep apnoea, $S B P$ systolic blood pressure, $D B P$ diastolic blood pressure, $P R$ pulse rate, $S D N N$ standard deviation of NN intervals, SDANN standard deviation of average NN intervals calculated over segments of 5 min, $p N N 50$ the percentage of consecutive RRs that differed by $>50 \mathrm{~ms}, r M S S D$ the square root of the mean squared differences of successive $\mathrm{NN}$ intervals, $L F$ low frequency, $H F$ high frequency

analysis of randomised controlled trials on the effects of exogenous melatonin at bedtime showed a significant reduction in nocturnal BP in subjects taking controlledrelease melatonin [32]. In people with tetraplegia, the melatonin pathway is impaired because the pineal gland is innervated by neurons from the superior cervical ganglia, which synapse with spinal sympathetic neurons at level C8T2. In injuries above that level, the pathway is affected resulting in a loss of the evening melatonin surge, which then leads to a diminished BP dip [33].

Interestingly, we found that in acute/intermediate SCI, the AHI was lowest among reverse dippers. However, without contemporaneous continuous BP and sleep data it is not appropriate to state conclusively that the $\mathrm{AHI}$ is lower in reverse dippers in the SCI population.

In summary, we propose that in the able-bodied population, OSA increases nocturnal BP by sympathetic activation. In people with high-level SCI, the disruption of sympathetic pathway causes a dissociation between the OSA and BP patterns.

\section{HRV vS. OSA}

Studies on the general population have revealed an altered pattern of HRV in people with OSA, with an increased nocturnal LF and LF/HF ratio [34]. One study comparing frequency domain indices between OSA subjects and controls during a controlled breathing period showed a significant reduction in HF modulation [35]. These results suggest an increased sympathetic activity during sleep and decreased vagal tone during the day in OSA patients. Because normal HRV is mediated by respiratory sinus arrhythmia, baroreflex-related fluctuation and thermoregulation-related fluctuation [34], the interpretation of nocturnal HRV could be confounded by multiple factors, including the presence of apnoeic/hypopnoeic events. As 
such, we only looked at the $24 \mathrm{~h} \mathrm{HRV}$ parameters and found no difference in either time domain or frequency domain analysis between people with non-OSA, mild, moderate and severe OSA.

From the autonomic cardiac control point of view, sympathetic neurons innervating the heart reside at T1-T5 level, and all our subjects had an injury level higher than T6. One study, which measured $24 \mathrm{~h}$ HRV on people with SCI showed a significantly higher $\mathrm{LF} / \mathrm{HF}$ ratio in people with lower level SCI (T6-T12) [36], indicating preserved sympathetic activity in this group.

The SDNN and SDANN represent the total variability of heart rate and are important predictors for cardiovascular risk [37]. We initially expected a reduction in SDNN and SDANN in people with severe OSA, hypothesising that the autonomic function in this group would be more compromised and hence a reduction in overall HRV observed. Conversely, the respiratory events could potentially contribute to an increased HRV overnight. However, our result showed no difference in these two parameters between OSA groups. Similar to the BP pattern, the HRV is largely controlled by the autonomic nervous system and the sympathetic pathway disturbance in SCI could explain the unresponsiveness of the sympathetic branch of HRV to apnoeic/hypopnoeic events. The parasympathetic branch, on the other hand, remains anatomically intact in SCI, but we did not see any significant impact of respiratory events on the HF power, which represents the vagal tone. We speculate that sympathetic and parasympathetic nervous systems act synergistically, and the level of tone in one component is dependent on the other [38]. In addition, the lack of response to respiratory events might itself be a sign of autonomic dysfunction. It might be of value to identify the apnoeic/hypopnoeic episodes and compare HRV within and without these episodes, to see whether there is any sympathetic response to hypoxia, desaturation and arousals, and any change in vagal tone due to lack of breathing. From the BP data, we speculate that there is no sympathetic activation during these episodes.

\section{Method consideration and limitations}

\section{Definition of 'day' and 'night' in ABPM studies}

Due to the lack of information on sleep/wake time for the ABPM study, we decided to a priori define 10 a.m.-8 p.m. as daytime and 12-6 a.m. as night-time for the following reasons: (1) after reviewing lights on and off time of the sleep study, we found the vast majority of our subjects went to bed before midnight (41/42), and all of them woke up by 10 a.m. Although the ABPM study was conducted on a different day, given that the two studies were done within 6 months, and the SCI population typically has a very regular routine, we assumed that they would have a similar sleep pattern. (2) This removes the morning and evening periods where most SCI participants have a usual routine requiring carers' assistance. These periods involve frequent posture change, showering, bowel care and other activities reported to be frequently associated with substantial cardiovascular instability. (3) There is evidence showing that a narrow fixed time is better than wide fixed time in prediction of the actual asleep and awake time [39]. Interestingly, the $24 \mathrm{~h} \mathrm{SBP}$ was higher than both daytime and night-time SBP in some groups and individuals, and warrants further investigation but is not within the scope of our study.

\section{Heterogeneity in sizes of subgroups}

The small number of non-OSA $(n=6)$ and dippers $(n=5)$ in our study group was associated with a potential risk of type II errors. This was expected since $92.9 \%$ of participants in our study were tetraplegic, and this was due to the high prevalence of OSA and BP non-dipping in this particular population. While we cannot exclude this possibility, our results were broadly consistent across the participants.

\section{Conclusion}

Both OSA and loss of nocturnal BP dipping are common in the SCI population. We found no relationship between BP pattern or HRV indices and presence or severity of OSA in people with SCI. The process of sympathetic activation following apnoeic/hypopnoeic events in the able-bodied population may be absent in SCI patients due to the loss of supraspinal sympathetic control and the disturbance of the spinal sympathetic pathway. Because of the dissociation between BP or HRV and OSA, it is not clear whether there is an association between autonomic dysfunction and OSA. In future studies, adding an able-bodied control group might be helpful.

Acknowledgements We thank Rachel Schembri and Marnie Graco for their assistance in data collection and Rachel Sore for her help in data analysis.

\section{Compliance with ethical standards}

Conflict of interest The authors declare that they have no conflict of interest.

\section{References}

1. Krassioukov A. Autonomic function following cervical spinal cord injury. Respir Physiol Neurobiol. 2009;169:157-64.

2. Teasell RW, Arnold JM, Krassioukov A, Delaney GA. Cardiovascular consequences of loss of supraspinal control of the 
sympathetic nervous system after spinal cord injury. Arch Phys Med Rehabil. 2000;81:506-16.

3. Chouchou F, Pichot V, Pepin JL, Tamisier R, Celle S, Maudoux $D$, et al. Sympathetic overactivity due to sleep fragmentation is associated with elevated diurnal systolic blood pressure in healthy elderly subjects: PROOF-SYNAPSE study. Eur Heart J. 2013;34:2122-31.

4. Dingli K, Assimakopoulos T, Wraith PK, fietze I, C W. Spectral oscillations of RR intervals in sleep apnoea/hypopnoea syndrome patients. Eur Respir J. 2003;22:943-50.

5. Guilleminault C, Poyares D, Rosa A, YS H. Heart rate variability, sympathetic and vagal balance and EEG arousals in upper airway resistance and mild obstructive sleep apnea syndromes. Sleep Med. 2005;6:451-7.

6. Hermida RC. Ambulatory blood pressure monitoring in the prediction of cardiovascular events and effects of chronotherapy: rationale and design of the MAPEC study. Chronobiol Int. 2007;24:749-75.

7. Kleiger RE, Stein PK, Bigger JT Jr. Heart rate variability: measurement and clinical utility. Ann Noninvasive Electrocardiol. 2005;10:88-101.

8. Ingelsson E, Bjorklund-Bodegard K, Lind L, Arnlov J, Sundstrom J. Diurnal blood pressure pattern and risk of congestive heart failure. JAMA. 2006;295:2859-66.

9. Bigger JT Jr., Fleiss JL, Steinman RC, Rolnitzky LM, Kleiger RE, Rottman JN. Frequency domain measures of heart period variability and mortality after myocardial infarction. Circulation. 1992;85:164-71.

10. Spicuzza L, Bernardi L, Calciati A, Di Maria GU. Autonomic modulation of heart rate during obstructive versus central apneas in patients with sleep-disordered breathing. Am J Respir Crit Care Med. 2003;167:902-10.

11. Kirshblum SC, Burns SP, Biering-Sorensen F, Donovan W, Graves DE, Jha A, Johansen M, et al. International standards for neurological classification of spinal cord injury (revised 2011). J Spinal Cord Med. 2011;34:535-46.

12. Head GA, McGrath BP, Mihailidou AS, Nelson MR, Schlaich MP, Stowasser M, et al. Ambulatory blood pressure monitoring in Australia: 2011 consensus position statement. J Hypertens. 2012;30:253-66.

13. The Report of an American Academy of Sleep Medicine Task Force. Sleep-related breathing disorders in adults: recommendations for syndrome definition and measurement techniques in clinical research. Sleep. 1999;22:667-89.

14. Rowland JW, Hawryluk G, Kwon B, Fehlings MG. Current status of acute spinal cord injury pathophysiology and emerging therapies: promise on the horizon. Neurosurg Focus. 2008;25:E2

15. Goh MY, Wong EC, Millard MS, Brown DJ, O'Callaghan CJ. A retrospective review of the ambulatory blood pressure patterns and diurnal urine production in subgroups of spinal cord injured patients. Spinal Cord. 2015;53:49-53.

16. Goh MY, Wong EC, Millard MS, Brown DJ, Berlowitz DJ, O'Callaghan CJ. Response to 'A retrospective review of sleep disordered breathing, hypertension and cardiovascular diseases in spinal cord injury patients'. Spinal Cord. 2015;53:498.

17. Sankari A, Martin JL, Badr M. A retrospective review of sleepdisordered breathing, hypertenstion and cardiovascular diseases in spinal cord injury patients. Spinal Cord. 2015;53:496-7.

18. Floras JS. Sleep apnea and cardiovascular risk. J Cardiol. 2014;63:3-8.

19. Somers VK, White DP, Amin R, Abraham WT, Costa F, Culebras A, et al. Sleep apnea and cardiovascular disease: an American Heart Association/american College Of Cardiology Foundation Scientific Statement from the American Heart Association Council for High Blood Pressure Research Professional Education
Committee, Council on Clinical Cardiology, Stroke Council, and Council On Cardiovascular Nursing. In collaboration with the National Heart, Lung, and Blood Institute National Center on Sleep Disorders Research (National Institutes of Health). Circulation. 2008;118:1080-111.

20. Chouchou F, Pichot V, Barthelemy JC, Bastuji H, Roche F. Cardiac sympathetic modulation in response to apneas/hypopneas through heart rate variability analysis. PLoS ONE. 2014;9: e86434.

21. Hubli M, Krassioukov AV. Ambulatory blood pressure monitoring in spinal cord injury: clinical practicability. J Neurotrauma. 2014;31:789-97.

22. Munakata M, Kameyama J, Kanazawa M, Nunokawa T, Moriai $\mathrm{N}$, Yoshinaga K. Circadian blood pressure rhythm in patients with higher and lower spinal cord injury: simultaneous evaluation of autonomic nervous activity and physical activity. J Hypertens. 1997;15:1745-9. 12 Pt 2

23. Rosado-Rivera D, Radulovic M, Handrakis JP, Cirnigliaro CM, Jensen AM, Kirshblum S, et al. Comparison of 24-hour cardiovascular and autonomic function in paraplegia, tetraplegia, and control groups: implications for cardiovascular risk. J Spinal Cord Med. 2011;34:395-403.

24. Goh MY, Millard MS, Wong EC, Brown DJ, Frauman AG, O'Callaghan CJ. Diurnal blood pressure and urine production in acute spinal cord injury compared with controls. Spinal Cord. 2017;55:39-46.

25. Seabra-Garcez JD, Matos-Souza JR, Goulart D, Pithon KR, Abib E, Etchebehere M, et al. Ambulatory blood pressure is associated with subclinical atherosclerosis in spinal cord injury subjects. Int J Cardiol. 2012;154:89-90.

26. Frisbie JH. Unstable baseline blood pressure in chronic tetraplegia. Spinal Cord. 2007;45:92-5.

27. Curt A, Nitsche B, Rodic B, Schurch B, Dietz V. Assessment of autonomic dysreflexia in patients with spinal cord injury. J Neurol Neurosurg Psychiatry. 1997;62:473-7.

28. Krum H, Louis WJ, Brown DJ, Jackman GP, Howes LG. Diurnal blood pressure variation in quadriplegic chronic spinal cord injury patients. Clin Sci (Colch). 1991;80:271-6.

29. Nitsche B, Perschak H, Curt A, Dietz V. Loss of circadian blood pressure variability in complete tetraplegia. J Hum Hypertens. 1996;10:311-7.

30. Fabbian F, Smolensky MH, Tiseo R, Pala M, Manfredini R, Portaluppi F. Dipper and non-dipper blood pressure 24-hour patterns: circadian rhythm-dependent physiologic and pathophysiologic mechanisms. Chronobiol Int. 2013;30:17-30.

31. Ekmekcioglu C, Thalhammer T, Mehrabi M, Glogar H, Holzenbein T, Markovic O, et al. The melatonin receptor subtype MT2 is present in the human cardiovascular system. J Pineal Res. 2003;35:40-44.

32. Grossman E, Laudon M, N Z. Effect of melatonin on nocturnal blood pressure: meta-analysis of randomized controlled trials. Vasc Health Risk Manag. 2011;7:577-84.

33. Zeitzer JM, Ayas NT, Shea SA, Brown R, Czeisler CA. Absence of detectable melatonin and preservation of cortisol and thyrotropin rhythms in tetraplegia. J Clin Endocrinol Metab. 2000;85:2189-96.

34. Park DH, Shin CJ, Hong SC, Yu J, Ryu SH, Kim EJ, et al. Correlation between the severity of obstructive sleep apnea and heart rate variability indices. J Korean Med Sci. 2008;23:226-31.

35. Wiklund U, Olofsson BO, Franklin K, Blom H, Bjerle P, Niklasson U. Autonomic cardiovascular regulation in patients with obstructive sleep apnoea: a study based on spectral analysis of heart rate variability. Clin Physiol. 2000;20:234-41.

36. Malmqvist L, Biering-Sorensen T, Bartholdy K, Krassioukov A, Welling KL, Svendsen JH, et al. Assessment of autonomic 
function after acute spinal cord injury using heart rate variability analyses. Spinal Cord. 2015;53:54-8.

37. Task force of the European Society of Cardiology, The North American Society of Pacing Electrophysiology. Heart Rate Variability. Standards of measurement, physiological interpretaion, and clinical use. Circulation. 1996;93:1043-65.
38. Grimm DR, De Meersman RE, Almenoff PL, Spungen AM, Bauman WA. Sympathovagal balance of the heart in subjects with spinal cord injury. Am J Physiol. 1997;272:H835-42. 2 Pt 2

39. Fagard R, Brguljan J, Thijs L, Staessen J. Prediction of the actual awake and asleep blood pressures by various methods of $24 \mathrm{~h}$ pressure analysis. J Hypertens. 1996;14:557-63. 